\title{
Effects of sodium valproate and carbamazepine on food competition aggression in pigeons
}

\section{Fachinelli ${ }^{1}$, M. Ahumada ${ }^{1}$, J.M. Fachinelli ${ }^{1}$, M. Torrecilla ${ }^{1}$ and E.L. Rodríguez-Echandía ${ }^{2}$}

\author{
${ }^{1}$ Laboratorio de Psicología Experimental y Comparada, \\ Universidad del Aconcagua and INCIHUSA (CRICYT), Mendoza, Argentina \\ ${ }^{2}$ Instituto de Medicina y Biología Experimental de Cuyo (IMBECU), \\ Facultad de Ciencias Médicas, Departamento de Patología, \\ Universidad Nacional de Cuyo, Mendoza, Argentina
}

\section{Correspondence \\ E.L. Rodríguez-Echandía \\ Casilla de Correo 33 \\ 5500-Mendoza \\ Argentina \\ Fax: +54-261-449-4047 \\ E-mail: erech@fmed2.uncu.edu.ar \\ Research supported by Consejo Nacional de Investigaciones \\ Científicas y Técnicas de Argentina (CONICET, PIP 4682/96) and by Aconcagua University and the National University of Cuyo, Mendoza, Argentina.}

Received June 23, 2006 Accepted March 7, 2007

\begin{abstract}
Valproate and carbamazepine (CAR) have been proposed as adjunct alternatives for the control of aggression in psychiatric patients, although no definite conclusions have been reached. We examined the effects of these drugs on food competition offensive aggression and other behaviors in high- and low-aggression food-restricted pigeons. These were divided into pairs containing previously ranked highaggression ( $\mathrm{N}=10$ pairs) and low-aggression females $(\mathrm{N}=10$ pairs $)$. In Experiment 1, a pigeon in each pair of high- and low-aggression subjects was treated daily with an oral dose of sodium valproate $(50 \mathrm{mg}$ $\mathrm{kg}^{-1} \mathrm{~mL}$ saline $\left.{ }^{-1}\right)$ for 15 days. The other animal received the vehicle. On days 1,7 , and 15 , food competition trials (10 $\mathrm{min}$ ) were performed 60 min after treatment. In Experiment 2, one pigeon in each pair was treated daily with an oral dose of CAR $\left(20 \mathrm{mg} \mathrm{kg}^{-1} \mathrm{~mL}\right.$ saline $\left.{ }^{-1}\right)$ for 15 days. Each pair was submitted to a food competition trial on days 1, 7, and 15 of treatment. Valproate (15 days of treatment) selectively decreased the time spent in offensive aggression (control: 102.7 $\pm 9.3 \mathrm{vs}$ valproate: $32.7 \pm 9.2 \mathrm{~s} ; \mathrm{P}<0.001$, ANOVA-2-TAU) of high-aggression pigeons. This was also the case for 7 and 15 days of CAR treatment (control: $131.5 \pm 8.9$ vs CAR: $60.4 \pm 5.3$, P < 0.01, and control: $122.7 \pm 7.1$ vs CAR: $39.1 \pm 5.2 ; \mathrm{P}<0.001$, ANOVA-2-TAU, respectively). Thus, the two anticonvulsive drugs have a similar effect on food competition aggression in pigeons.
\end{abstract}

\section{Introduction}

Some anticonvulsive drugs such as sodium valproate and carbamazepine have been proposed as adjunct alternatives for the control of agitation, wandering, and violence in psychiatric patients. Partially positive results have been obtained with these drugs regarding aggressive and impulsive behaviors in personality disorders (see Ref. 1), dementia
Key words

- Valproate

- Carbamazepine

- Aggressive behavior

- Food competition

- Pigeons 
tion interaction test performed with food-restricted pigeons is a useful animal model for the study of offensive and defensive social aggression (7). Using this test we have shown that the behavioral response of male and female pigeons to some psychoactive drugs is related to their natural aggressiveness exhibited prior to the treatments (8-10). To our knowledge, however, no analysis has been reported of the effect of valproate and carbamazepine on this type of aggressive behavior in pigeons. In this species, valproate has been used mainly for studies on learning (11), matching-to-sample performance (12), and drug discrimination properties (13). In addition, we are not aware of the use of carbamazepine in pigeons.

The purpose of the present study was to examine the effects of acute, subchronic and chronic sodium valproate (Experiment 1), and carbamazepine (Experiment 2) on the aggressive and general behavior responses of food-restricted high- and low-aggression female pigeons exposed to food competition interactions.

\section{Material and Methods}

\section{Subjects}

The subjects were mature wild-female domestic pigeons (Columba livia) weighing 350-400 g. They were captured on the University Campus during the winter season (short daylight hours and low sex hormone levels in pigeons) and reared singly in $50 \mathrm{x}$ $40 \times 40$-cm cages that were visually isolated from one another for 30 days. The animal room was kept at constant temperature (24 \pm $3^{\circ} \mathrm{C}$ ) and lighting (lights on from 8:00 to 19:00 h). Food (a mixture of grains) and water were available ad libitum. On day 31 , pigeons were weighed (basal weight). Thereafter, the food given was calculated to maintain subjects at $80 \%$ of basal weight. Water was provided ad libitum. All experimental treatments were approved by the Animal
Welfare Committee of the National University of Cuyo Medical School.

\section{Interaction cage}

The dimensions of the interaction cage were: $2.0 \times 2.0$ (base) $\times 2.0$ (height) m, with four $35-\mathrm{cm}$ high legs. The floor was covered with chaff. The inner walls were painted white. The front wall had a 1.35 x $0.41-\mathrm{m}$ dark glass window allowing direct observation of animal behavior without visual disturbance. To induce fighting, a feeder was placed at the center of the arena. The feeder was a $25-\mathrm{cm}$ high pyramid with a short lateral arm bearing a single $2.0-\mathrm{cm}$ hole through which just one animal could freely eat a mixture of grains. Previous reports have shown that dominance for feeder control rapidly develops in pairs of food-restricted pigeons exposed to food competition interactions (7). In order to habituate the pigeons to the interaction cage, all animals were individually submitted to a daily 20 min exposure to the arena 15 days before ranking.

\section{Ranking method}

All agonistic interactions involving a real or potential risk to the opponent pigeon were considered to be offensive behavior (see Table 1). In order to estimate the spontaneous aggression levels of the captured birds, each one was ranked daily in the interaction cage (5-min trials) for 6 consecutive days in the presence of another bird which was a different one for each day. The experienced observers were $0.30 \mathrm{~m}$ away from the front of the interaction cage.

Females showing a mean time spent in offensive aggression exceeding $60 \mathrm{~s} / 5 \mathrm{~min}$ over the six-test sessions were arbitrarily ranked as "high-aggression subjects". Pigeons with the shortest offensive aggression time (less than $10 \mathrm{~s} / 5 \mathrm{~min}$ ) were ranked as "low-aggression subjects". A total of 40 pairs 
of similar offensive aggression scores were obtained.

\section{Experiment 1. Sodium valproate treatment}

The literature indicates that the valproate doses used in pigeons range from 20 to 120 $\mathrm{mg} / \mathrm{kg}$ (11-13). In preliminary dose-response experiments we found that acute oral doses of $20-50 \mathrm{mg} / \mathrm{kg}$ did not impair the general performance of pigeons, as was the case after larger doses (80-100 mg/kg), causing a dose-related blockade of eating behavior. In the experiments reported here, one pigeon in each pair of high-aggression $(\mathrm{N}=10$ pairs $)$ and low-aggression subjects ( $\mathrm{N}=10$ pairs) was treated daily with an oral dose of sodium valproate $\left(50 \mathrm{mg} \mathrm{kg}^{-1} \mathrm{~mL}^{-1}\right)$ for 15 days. The other member of the pair received $1 \mathrm{~mL}$ of vehicle. Each pair was exposed to a food competition trial (10 min) $60 \mathrm{~min}$ after the oral dose of valproate on day 1 (acute treatment), day 7 (subchronic treatment) and day 15 (chronic treatment). The time during which the animals exhibited offensive behavior, emotional behavior, feeder control behavior, and eating behavior was measured by a well-trained observer who was blind to the treatment conditions. Time was recorded on a PC using software designed by us. The specific behaviors recorded for each category are listed in Table 1. Offensive aggression is reported as: a) total time spent/10 min in all forms of these behaviors, and b)

Table 1. Structure of the pigeon behaviors selected for recording.

1. Offensive behavior: time spent $(\mathrm{s} / 10 \mathrm{~min})$ in agonistic interactions involving a real or potential risk to the opponent pigeon.

- Pursuing: to follow in order to attack or cause running away in the opponent.

- Hooking: to attack with a wing to hold the opponent.

- Pecking: to pick up with the beak preventing opponent's access to food, or in areas far from food, after chasing (to follow quickly in order to harm).

- Wing beating: to hit with the wings.

- Aggressive vocalization: vocalizations close to feeder or in areas far from food, together with horizontal movements of head and body causing wing tremor in opponent or running away in the opponent.

- Threatening: to express intention to inflict injury causing freezing or running away in the opponent.

2. Emotional behavior: time spent $(\mathrm{s} / 10 \mathrm{~min}$ ) in behaviors involving fear and anxiety responses following offensive acts of the opponent.

- Watching: close observation of the opponent for a time.

- Wing tremor: after an attack or aggressive vocalizations of the opponent.

- Fear vocalizations: short vocalizations accompanied by expiration and immobility after an aggressive attack by the opponent.

- Freezing-like behavior in a corner of the interaction cage (far from feeder).

- Intents to leave the observation chamber (flying up to the top of the chamber).

3. Feeder control behavior (standard laboratory measure of dominance): time spent (s/10 $\mathrm{min}$ ) in:

- Eating attempts: up and down of the head at the feeder without eating.

- Pushing the opponent out of the feeder.

- Wing covering the feeder.

- Walking around the feeder.

- Vigilance/immobility close to the feeder to prevent eating at the feeder by the opponent.

4. Eating behavior: time spent $(\mathrm{s} / 10 \mathrm{~min})$ in:

- Eating at the feeder.

- Eating out of the feeder (food from the feeder on the surrounding floor).

5. Resting behavior: time spent ( $\mathrm{s} / 10 \mathrm{~min})$ in: - Resting (sedate). 
structure of offensive behavior (time spent in each component of the behavior). The other behavioral categories are reported as total time spent.

\section{Experiment 2. Carbamazepine treatment}

Non-sedative doses of carbamazepine used in mammals for testing aggressive behavior ranged from 5 to $50 \mathrm{mg} / \mathrm{kg}(14,15)$. In preliminary dose-response experiments we found that acute doses exceeding $20 \mathrm{mg} / \mathrm{kg}$ cause a dose-related locomotor ataxia and

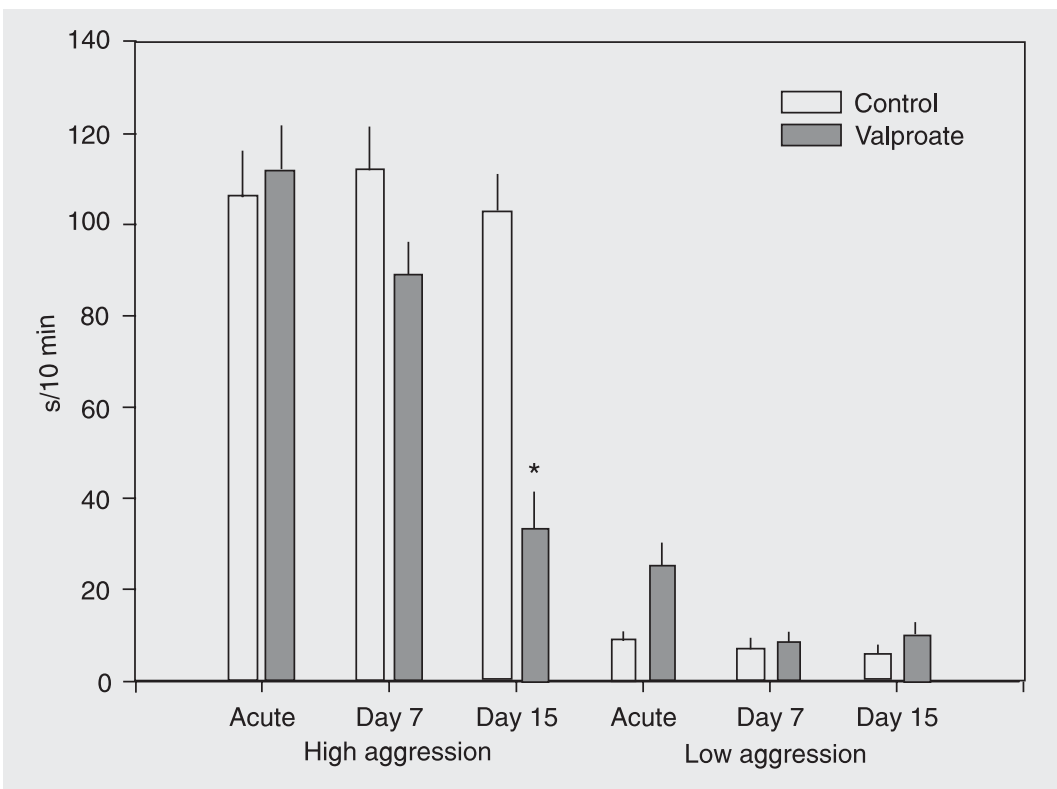

Figure 1. Acute, day 7 and day 15 effect of valproate treatment $(50 \mathrm{mg} / \mathrm{kg})$ on the total time spent by high- ( $\mathrm{N}=10$ pairs) and low-aggression pigeons ( $\mathrm{N}=10$ pairs) in offensive aggression. Data are reported as means \pm SEM. ${ }^{*} \mathrm{P}<0.001$ vs control (TAU test).

Table 2. Time spent by control and valproate-treated (15 days) high- and low-aggression pigeons in various behaviors.

\begin{tabular}{lccccc}
\hline \multirow{2}{*}{ Behavior } & \multicolumn{2}{l}{ High aggression $(\mathrm{N}=10$ pairs $)$} & & \multicolumn{2}{c}{ Low aggression $(\mathrm{N}=10$ pairs $)$} \\
\cline { 2 - 3 } \cline { 6 - 7 } & Control & Valproate & & Control & Valproate \\
\hline Emotion & $16.3 \pm 1.9$ & $20.0 \pm 2.3$ & & $23.4 \pm 4.0$ & $21.6 \pm 3.8$ \\
Resting & $35.6 \pm 5.7$ & $64.2 \pm 15.7$ & & $171.5 \pm 30.9$ & $145.8 \pm 29.6$ \\
Feeder control & $18.2 \pm 4.2$ & $30.6 \pm 8.7$ & & $16.7 \pm 5.7$ & $25.2 \pm 12.8$ \\
Eating & $424.0 \pm 42.3$ & $407.8 \pm 38.6$ & & $307.3 \pm 30.5$ & $316.1 \pm 32.3$
\end{tabular}

Data are reported as mean \pm SEM s/10 min. drowsiness in pigeons. In the present experiment, one pigeon in each pair of high-aggression $(\mathrm{N}=10$ pairs $)$ and low-aggression birds $(\mathrm{N}=10$ pairs $)$ was treated daily with an oral dose of carbamazepine $\left(20 \mathrm{mg} \mathrm{kg}^{-1} \mathrm{~mL}\right.$ saline $^{-1}$ ) for 15 days. The other member of the pair received $1 \mathrm{~mL}$ of vehicle. Each pair was submitted to a food competition trial on days 1,7 , and 15 of treatment as done in Experiment 1.

\section{Statistical analysis}

Comparisons between the mean behavioral scores of experimental (drug-treated) animals and their controls obtained in the trials of days 1,7 , and 15 were analyzed by repeated measure ANOVA-2 and the post hoc TAU multiple comparisons test, with the level of significance set at $\mathrm{P}<0.05$. Data are reported as means \pm SEM throughout the text and figures.

\section{Results}

\section{Experiment 1. Effects of sodium valproate} treatment

After data analysis by ANOVA-2, with treatment $v s$ time as factors, there was a significant variation according to treatment $((\mathrm{F}=49.23$, d.f. $=1.54, \mathrm{P}<0.005)$, time $(\mathrm{F}=$ 48.98, d.f. $=2.54, \mathrm{P}<0.005)$ and interaction $(\mathrm{F}=37.76$, d.f. $=2.54, \mathrm{P}<0.005)$.

Figure 1 shows no difference in the scores of total time spent in offensive aggression between the acute valproate and control groups of high-aggression females. In these pigeons, subchronic valproate caused only a trend toward lower offensive aggression scores. However, the inhibition of offensive aggression reached significance when the chronic treatment scores ( 15 days) were compared (TAU: P < 0.001). Analysis of the structure of offensive aggression in the chronically treated animals showed significantly lower scores of hooking (control: 25.7 
$\pm 2.0 v s$ valproate: $3.2 \pm 0.7 \mathrm{~s} / 10 \mathrm{~min} ; \mathrm{P}<$ 0.05 ) and aggressive vocalizations (control: $11.1 \pm 0.8 v s$ valproate $2.0 \pm 0.3 ; \mathrm{P}<0.05$ ) and a trend toward lower scores of pecking (control: $18.2 \pm 3.5 v s$ valproate: $10.8 \pm 4.0$ ), wing beating (control: $4.0 \pm 1.2 \mathrm{vs}$ valproate: $1.2 \pm 0.6$ ), threatening (control: $18.5 \pm 3.6 v \mathrm{~s}$ valproate: $8.2 \pm 2.3$ ), and pursuing (control: $13.0 \pm 5.4 v s$ valproate: $5.8 \pm 1.1$ ).

The time spent by high-aggression pigeons in emotional behavior, feeder control behavior, eating behavior, and immobility time was not changed by chronic valproate treatment (Table 2).

The scores of total time spent in offensive aggression by low-aggression control pigeons were very low. The acute, subchronic and chronic valproate treatment did not affect offensive aggression in these animals (Figure 1). The same was true for running away behavior, feeder control behavior, eating behavior, and immobility time (Table 2).

\section{Experiment 2. Effects of carbamazepine treatment}

After data analysis by ANOVA-2, with treatment $v s$ time as factors, there was a significant variation according to treatment $(\mathrm{F}=561.71$, d.f. $=1.54, \mathrm{P}<0.001)$, time $(\mathrm{F}$ $=48.98$, d.f. $=2.54, \mathrm{P}<0.001)$ and interaction $(\mathrm{F}=79.89$, d.f. $=2.54, \mathrm{P}<0.001)$.

Figure 2 shows that acute treatment with carbamazepine had no effect on the behaviors scored for the high-aggression pigeons. The 7-day and the 15-day treatments, however, were effective in decreasing significantly the scores of offensive aggression (TAU: $\mathrm{P}<0.01$ and 0.001 , respectively) in these animals, without affecting the other behaviors scored (Table 3). Analysis of the structure of offensive aggression in the 15day treatments revealed significantly lower scores of hooking (control: $39.7 \pm 3.2 \mathrm{vs}$ carbamazepine: $11.7 \pm 1.9 ; \mathrm{P}<0.03)$ and aggressive vocalizations (control: $25.1 \pm 1.9$ vs carbamazepine: $8.3 \pm 1.4 ; \mathrm{P}<0.05)$ and only a trend toward lower pursuing (control: $15.3 \pm 3.2 v s$ carbamazepine: $8.1 \pm 2.4$ ), pecking (control: $5.0 \pm 0.8$ vs carbamazepine: $3.2 \pm 0.6$ ) and wing beating (control: $7.1 \pm 1.9 v s$ carbamazepine: $2.5 \pm 0.6$ ) scores. In the group of low-aggression subjects the acute, subchronic and chronic carbamazepine treatments did not affect any behavior scored (Figure 2 and Table 3).

\section{Discussion}

The present results show that chronic sodium valproate $\left(50 \mathrm{mg} \mathrm{kg}^{-1}\right.$ day $\left.^{-1}\right)$ selec-

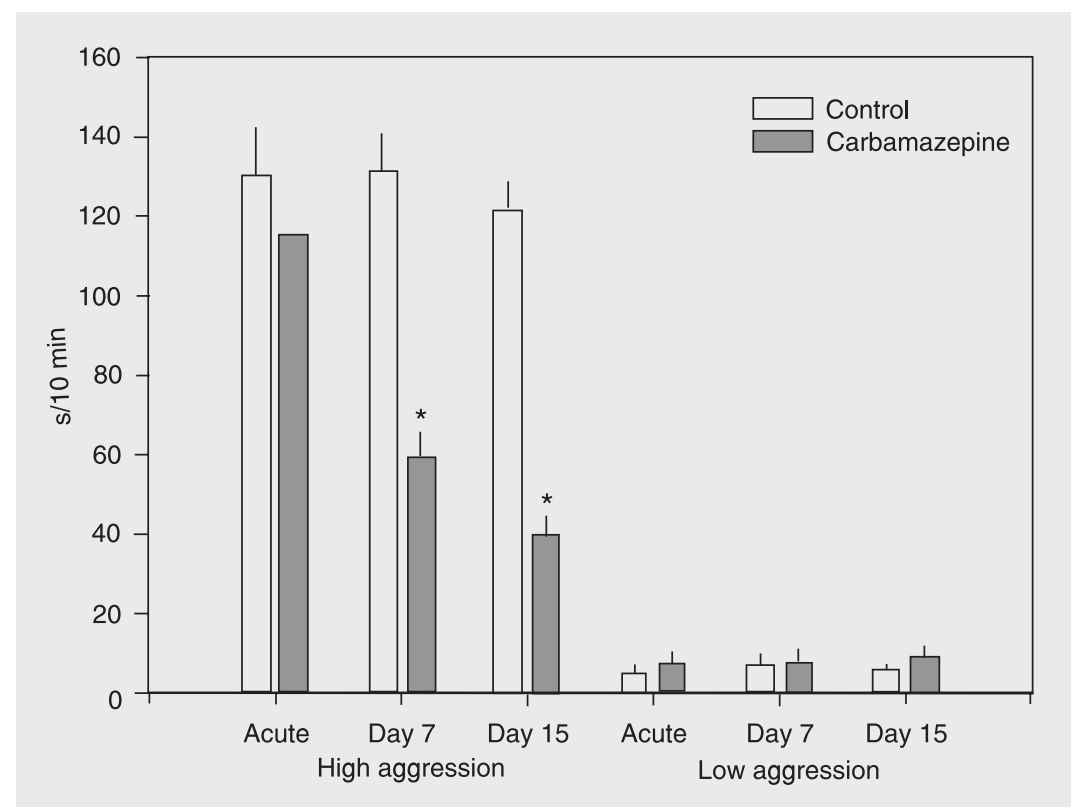

Figure 2. Acute, day 7 , and day 15 effect of carbamazepine treatment $(20 \mathrm{mg} / \mathrm{kg})$ on the total time spent by high- ( $\mathrm{N}=10$ pairs) and low-aggression pigeons ( $\mathrm{N}=10$ pairs $)$ in offensive aggression. Data are reported as means $\pm \mathrm{SEM}$. ${ }^{*} \mathrm{P}<0.01 \mathrm{vs}$ control (TAU test).

Table 3. Time spent by control and carbamazepine-treated (15 days) high- and lowaggression pigeons in various behaviors.

\begin{tabular}{lccccc}
\hline Behavior & \multicolumn{2}{l}{ High aggression $(\mathrm{N}=10$ pairs $)$} & & \multicolumn{2}{c}{ Low aggression ( $\mathrm{N}=10$ pairs) } \\
\cline { 2 - 3 } \cline { 6 - 6 } & Control & Carbamazepine & & Control & Carbamazepine \\
\hline Emotion & $24.3 \pm 4.8$ & $37.2 \pm 8.3$ & & $20.5 \pm 8.4$ & $45.8 \pm 12.3$ \\
Resting & $20.6 \pm 4.5$ & $28.4 \pm 5.2$ & & $66.6 \pm 2.8$ & $65.3 \pm 32.8$ \\
Feeder control & $38.7 \pm 9.4$ & $40.0 \pm 9.8$ & & $23.7 \pm 6.5$ & $20.2 \pm 5.5$ \\
Eating & $354.6 \pm 49.8$ & $417.3 \pm 41.7$ & & $407.2 \pm 36.3$ & $376.7 \pm 34.8$ \\
\hline
\end{tabular}

Data are reported as mean $\pm \mathrm{SEM} \mathrm{s} / 10 \mathrm{~min}$. 
tively decreased the time spent in offensive aggression without affecting the other behaviors scored for the food-restricted highaggression pigeons exposed to food competition interactions. In the low-aggression pigeons, chronic valproate did not affect any of the scored behaviors. This was also the case for subchronic and chronic carbamazepine treatment. In addition, both valproate and carbamazepine shared similar effects on the structure of offensive behavior in the high-aggression pigeons. Though only hooking and aggressive vocalizations were significantly inhibited, all other components of this behavior were reduced by these drugs. Therefore, the two anticonvulsive drugs have similar behavioral profiles, although carbamazepine administration was followed more rapidly by antiaggressive effects in the highaggression pigeons (7-day treatment) than valproate (15-day treatment). We speculate that the lack of a decrease in aggressive responses in low-aggression pigeons after chronic valproate and subchronic and chronic carbamazepine treatment might be attributed to the low-baseline levels of aggressiveness of these animals.

The mechanism of the anticonvulsive action of valproate is centered on interactions with voltage-sensitive $\mathrm{Na}^{+}$channels and enhancement of brain GABA accumulation due to stimulation of GABAdecarboxylase and inhibition of GABAtransaminase (see Ref. 16). The mechanism by which valproate can exert antiaggressive actions is poorly known. In rats, a linear correlation was observed between GABA levels in the olfactory bulbs and inhibition of mouse killing behavior following local injection of valproic acid and gamma-vinyl GABA (17). This suggests an inhibitory role of GABA from the olfactory bulbs in the modulation of muricidal behavior. As to carbamazepine, it can decrease resting sodium fluxes as well as sodium currents that flow during action potentials (see Ref. 16). In addition, carbamazepine was shown to increase the firing rate of noradrenaline neurons in the locus ceruleus (18) and to inhibit 5-hydroxytryptophan (5-HTP)-evoked head twitches (19) in the rat. It has also been reported that the antiaggressive effect of carbamazepine in mice is somehow related to its agonistic action on adenosine receptors (20) and to GABAergic mechanisms (15).

Little is known about the mechanisms responsible for the antiaggressive effects of valproate and carbamazepine. We have reported that subchronic treatment with diazepam inhibits offensive aggression and emotional responses in high-aggression pigeons. In contrast, this treatment causes a significant increase in the scores of offensive aggression in low-aggression pigeons (9). Acute treatment with the opiate receptor antagonist, naloxone, is also able to block food competition aggression in high-aggression pigeons, whereas it stimulates offensive aggression in low-aggression pigeons (10). This evidence shows that the offensive behavior responses of pigeons to brain GABA-Abenzodiazepine receptor agonists as well as to opiate receptor antagonists may be exactly opposite in naturally high- and lowaggression pigeons. It has been reported that some drugs (e.g., methamphetamine) increase the rate of behavior that customarily occurs at a low rate and decreases the rate of behavior that customarily occurs at a high rate in pigeons (see Ref. 21). This might be the case also for the effect of diazepam and naloxone on aggression. This was not the case, however, for valproate and carbamazepine, suggesting a mechanism of action independent of GABA-A-benzodiazepine receptors and opiate receptors for the antiaggressive properties of these drugs. However, the results do not preclude a potential contribution of other diazepam-insensitive benzodiazepine sites on GABA-A receptors. In pigeons, the density of the latter is approximately $10-20 \%$ of total benzodiazepine receptor binding in the olfactory bulb, hippocampus, thalamic nuclei, and cerebellar granule cells (22). 
As shown here for valproate and carbamazepine, both subchronic and chronic treatments with the 5-hydroxytryptamine precursor, 5-HTP, have been reported to block food competition aggression in high-aggression pigeons without changing aggressive responses in low-aggression pigeons (8). This might suggest that the effects of these drugs could implicate a stimulation of brain 5-HT systems. However, it was reported that carbamazepine inhibits head twitches evoked by 5 -HTP in the rat (19). This evidence is against the involvement of a serotonergic stimulation in the antiaggressive action of carbamazepine on high-aggression pigeons. As to valproate, to our knowledge, serotonergic actions have not been reported for this drug. The mechanism of the antiaggressive action of carbamazepine and sodium valproate on high-aggression pigeons still remains to be investigated.

\section{Acknowledgments}

The authors wish to thank Dr. Fabio Sacerdote for a critical reading of the text and Mrs. María Patricia Zapata for assistance with the preparation of the manuscript.

\section{References}

1. Pelissolo A, Lepine JP. Pharmacotherapy in personality disorders: methodological issues and results. Encephale 1999; 25: 496-507.

2. Herrmann N. Recommendations for the management of behavioral and psychological symptoms of dementia. Can J Neurol Sci 2001; 28 (Suppl 1): S96-S107.

3. Ruedrich S, Swales TP, Fossaceca C, Toliver J, Rutkowski A. Effect of divalproex sodium on aggression and self-injurious behaviour in adults with intellectual disability: a retrospective review. $J$ Intellect Disabil Res 1999; 43 (Part 2): 105-111.

4. Azouvi P, Jokic C, Attal N, Denys P, Markabi S, Bussel B. Carbamazepine in agitation and aggressive behaviour following severe closed-head injury: results of an open trial. Brain Inj 1999; 13: 797804.

5. Wroblewski BA, Joseph AB, Kupfer J, Kalliel K. Effectiveness of valproic acid on destructive and aggressive behaviours in patients with acquired brain injury. Brain Inj 1997; 11: 37-47.

6. Lindenmayer JP, Kotsaftis A. Use of sodium valproate in violent and aggressive behaviors: a critical review. J Clin Psychiatry 2000; 61: 123-128.

7. Fachinelli C, Sargo S, Bataller R, Rodriguez Echandia EL. Effect of 5-HTP and ketanserine on the aggressive reaction induced by food competition in dominant and submissive pigeons (Columba livia). Behav Brain Res 1989; 35: 265-270.

8. Fachinelli C, Ison M, Rodriguez Echandia EL. Effect of subchronic and chronic exposure to 5-hydroxytryptophan (5-HTP) on the aggressive behavior induced by food competition in undernourished dominant and submissive pigeons (Columba livia). Behav Brain Res 1996; 75: 113-118.

9. Fachinelli C, Ison M, Rodriguez Echandia EL. Effects of diazepam and flumazenil on food competition behavior in high- and low-aggression pigeons. Pharmacol Biochem Behav 2003; 74: 765-770.

10. Fachinelli $C$, Torrecillas M, Rodriguez Echandia EL. Effect of naloxone on food competition aggression in food-restricted high and low aggression pigeons (Columba livia). Braz J Med Biol Res 2004; 37: 347-351.

11. Poling A, Blakely E, White W, Picker M. Chronic effects of clonazepam, phenytoin, ethosuximide, and valproic acid on learning in pigeons as assayed by a repeated acquisition procedure. Pharmacol Biochem Behav 1986; 24: 1583-1586.

12. Karas CA, Picker M, Poling A. Effects of phenobarbital in combination with phenytoin or valproic acid on the delayed-matching-tosample performance of pigeons. Pharmacol Biochem Behav 1986; 25: 929-932.

13. Picker M, Wallace S, Hancock S, Poling A. Discriminative stimulus properties of valproic acid in the pigeon. Psychopharmacology 1985; 87: 449-453.

14. Tannhauser SL, Tannhauser M, Barros HM, Corso CO, Pinto-Netto LM. Effects of carbamazepine or imipramine alone or in association with amphetamine on the fighting time of REM sleep-deprived rats. Braz J Med Biol Res 1984; 17: 179-184.

15. Nakao K, Higashio T, Inukai T. Antagonism of picrotoxin against the taming effect of carbamazepine on footshock induced fighting behavior in mice. Jpn J Pharmacol 1985; 39: 281-283.

16. Gilman GA, Ruddon RW, Molinof PB. The pharmacological basis of therapeutics. 9th edn. New York: McGraw Hill Co.; 1996.

17. Molina V, Ciesielski L, Gobaille S, Mandel P. Effects of the potentiation of the GABAergic neurotransmission in the olfactory bulbs on mouse-killing behavior. Pharmacol Biochem Behav 1986; 24: 657664.

18. Olpe HR, Jones RS. The action of anticonvulsant drugs on the firing of locus coeruleus neurons: selective, activating effect of carbamazepine. Eur J Pharmacol 1983; 91: 107-110.

19. Maj J, Chojnacka-Wojcik E, Lewandowska A, Tatarczynska E, Wiczynska B. The central action of carbamazepine as a potential antidepressant drug. Pol J Pharmacol Pharm 1985; 37: 47-56.

20. Fujiwara Y, Takeda T, Kazahaya Y, Otsuki S, Sandyk R. Inhibitory effects of carbamazepine on clonidine-induced aggressive behavior in mice. Int $J$ Neurosci 1988; 42: 77-84.

21. Acri JB, Wong G, Lyon T, Witkin JM, Basile AS. Localization and pharmacological characterization of pigeon diazepam-insensitive GABAA receptors. Neuroscience 1997; 77: 371-378.

22. Odum AL, Lieving LM, Schaai DW. Effects of D-amphetamine in a temporal discrimination procedure: selective changes in timing or rate dependency? J Exp Anal Behav 2002; 78: 195-214. 